\title{
Tuning of Optical Properties and Thermal Cycloreversion Reactivity of Photochromic Diarylbenzene by Introducing Electron-Donating Substituents
}

\section{Tatsumoto Nakahama, Daichi Kitagawa, Seiya Kobatake}

\begin{tabular}{|c|c|}
\hline Citation & Journal of Physical Chemistry C. 123(51); 31212-31218 \\
\hline Issue Date & 2019-11-27 \\
\hline Type & Journal Article \\
\hline Textversion & Author \\
\hline $\begin{array}{l}\text { Supporting } \\
\text { Information }\end{array}$ & $\begin{array}{l}\text { The Supporting Information is available free of charge at } \\
\text { https://doi.org/10.1021/acs.jpcc.9b09953. } \\
\text { • Syntheses of 1,2-diarylbenzene derivatives and detailed experimental data (Figures } \mathrm{S} 1- \\
\text { S14 and Tables S1-S19) (PDF) } \\
\text { - Compound 4a in n-hexane underwent the photochromic reaction involving a color } \\
\text { change from colorless to green when the solution was irradiated at } 365 \mathrm{~nm} \text { (Video S1) } \\
\text { (AVI) }\end{array}$ \\
\hline Rights & $\begin{array}{l}\text { This document is the Accepted Manuscript version of a Published Work that appeared in } \\
\text { final form in Journal of Physical Chemistry C, copyright (C) American Chemical Society } \\
\text { after peer review and technical editing by the publisher. To access the final edited and } \\
\text { published work see https://doi.org/10.1021/acs.jpcc.9b09953. }\end{array}$ \\
\hline DOI & 10.1021/acs.jpcc.9b09953 \\
\hline
\end{tabular}

\section{Self-Archiving by Author(s) \\ Placed on: Osaka City University}

NAKAHAMA, T., KITAGAWA, D., \& KOBATAKE, S. (2019). Tuning of Optical Properties and Thermal Cycloreversion Reactivity of Photochromic Diarylbenzene by Introducing Electron-Donating Substituents. The Journal of Physical Chemistry C. 123, 31212-31218. doi:10.1021/acs.jpcc.9b09953 


\section{Tuning of Optical Properties and Thermal}

\section{Cycloreversion Reactivity of Photochromic}

\section{Diarylbenzene by Introducing Electron-Donating}

\section{Substituents}

Tatsumoto Nakahama, Daichi Kitagawa* and Seiya Kobatake*

Department of Applied Chemistry, Graduate School of Engineering, Osaka City University, 3-3138 Sugimoto, Sumiyoshi-ku, Osaka 558-8585, Japan.

\footnotetext{
ABSTRACT

Thermally reversible photochromic compounds having excellent physicochemical properties can be exploited for many practical applications, such as ophthalmic lenses, real-time holography, and super-resolution microscopy. In this study, we have designed and synthesized novel 1,2diarylbenzene derivatives bearing various electron-donating substituents at $p$-position of the
} 
phenyl ring to tune the optical and thermal properties for the practical applications. Introduction of the electron-donating groups resulted in the red-shift of the absorption spectra, increase in the absorption coefficients of the open-ring isomers, and deceleration of the thermal cycloreversion of the closed-ring isomers. Theoretical analysis based on Hammett's substituent constant and density functional theory revealed that the rate of thermal cycloreversion became lower in proportion to the electron-donating ability of the substituent. The novel 1,2-diarylbenzene derivatives synthesized here could undergo photocyclization upon irradiation with UV-A light and fast thermal cycloreversion with a half-life of a few hundred milliseconds to seconds.

\section{Introduction}

Photochromic compounds undergoing reversible transformation between two isomers with different absorption spectra upon photoirradiation have attracted significant attention, because various physicochemical properties, such as conductivity, fluorescence, and magnetism, can be modulated without any direct physical contact. ${ }^{1-3}$ Thermally reversible (T-type) photochromic molecules are promising materials for ophthalmic lenses ${ }^{4}$, photoactuators ${ }^{5-6}$, and so on. Azobenzene, spiropyran, and naphthopyran are some of the representative T-type photochromic compounds. During last two decades, several kinds of T-type photochromic compounds undergoing fast thermal bleaching with half-life $\left(t_{1 / 2}\right)$ of a few seconds or below at room temperature have been reported. Abe and co-workers developed specifically hexaarylbiimidazole derivatives, that have $t_{1 / 2}$ of a few tens of milliseconds or nanoseconds for thermal bleaching, by inhibiting the diffusion of radicals by crosslinking two imidazole units..$^{7-10}$ They were applied to real-time holography. ${ }^{11-12}$ Raymo et al. reported oxazine derivatives with $t_{1 / 2}$ of a few tens of

nanoseconds, ${ }^{13-14}$ and achieved super-resolution imaging using the oxazine derivative linked to a 
fluorescent dye. ${ }^{15-16}$ Thus, T-type photochromic compounds undergoing fast thermal bleaching are of great interest for the various applications.

On the other hand, photochemically reversible (P-type) photochromic compounds are also gaining significant attention for optical memory media, ${ }^{2,17}$ switching devices, ${ }^{18}$ display materials, ${ }^{19}$ and non-linear optics. ${ }^{20}$ Diarylethene (DAE) is one of the most promising P-type photochromic compounds because of their excellent properties such as high durability, high sensitivity, rapid response, and high reactivity in the solid state. ${ }^{21}$ If DAE can be converted to T-type photochromic compound, a new family of T-type photochromic switch with the excellent properties mentioned above can be created. Although various approaches have been adopted to accelerate the thermal cycloreversion of DAEs, ${ }^{22-23}$ there are only a few studies on DAE that undergoes thermal cycloreversion with half-life $\left(t_{1 / 2}\right)$ of the order of seconds at room temperature. ${ }^{24-27}$

Very recently, we have succeeded in developing a T-type photochromic compound, 1,2diarylbenzene $(\mathrm{DAB})$ by only introducing a tetrafluorobenzene ring to the ethene bridge of a representative DAE, 1,2-bis(2-methyl-5-phenyl-3-thienyl)perfluorocyclopentene (Scheme 1). ${ }^{28}$ DAB (1a) undergoes photocyclization upon irradiation with ultraviolet (UV) light and fast thermal cycloreversion with a $t_{1 / 2}$ of $130 \mathrm{~ms}$ at $298 \mathrm{~K}$. However, 1a has several limitations in practical applications such as photochromic ophthalmic lenses. Specifically, 1a has almost no absorption in the UV-A region (315-400 nm), and the absorbance at visible region of the closed-ring isomer $\mathbf{1 b}$ upon irradiation with UV $(313 \mathrm{~nm})$ light is very small because of the extremely rapid thermal cycloreversion. Several approaches to overcome this drawback can be proposed based on the studies on DAEs. ${ }^{29-30}$ The absorption spectrum of DAE open-ring isomer can be red-shifted by extending the $\pi$-conjugation. ${ }^{29}$ Besides, changing the aryl moiety from the thiophene ring to an aromatic ring with lower aromatic stabilization energy could decelerate the thermal cycloreversion 
of DAE closed-ring isomer. ${ }^{30}$ However, a combination of the multiple molecular modifications may make the prediction of physicochemical properties difficult, because it may simultaneously affect many properties. Hence, a rational designing of the molecules is highly sought after.

Irie and coworkers reported that the introduction of electron-donating substituents at $p$-position of the phenyl rings of a DAE derivative, 1,2-bis(2,4-dimethyl-5-phenyl-3thienyl)perfluorocyclopentene, leads to a red-shift in the absorption spectrum of the open-ring isomer and increases of the absorption coefficient while maintaining the photocyclization quantum yield. ${ }^{31}$ Moreover, the thermal cycloreversion of DAE closed-ring isomers becomes slow when electron-donating groups are introduced in the aryl groups. ${ }^{32}$ If the introduction of electrondonating groups confers the same properties to $\mathrm{DAB}$, as those conferred to DAE, an effective method for improving the physicochemical properties of DAB can be established. Considering this, here, we have introduced electron-donating groups at the $p$-position of the phenyl rings of 1a, with the aim of addressing the problems arising because of multiple molecular modifications.

In this work, we have designed and synthesized novel DABs $\mathbf{2 a - 4 a}$ having $N, N$-diphenylamino, methoxy, or $N, N$-dimethylamino groups as the electron-donating substituents at the $p$-position of the phenyl rings (Scheme 1). The photochromic and thermal properties in solution were investigated, and the synthesized compounds exhibited the desired optical properties and thermal cycloreversion reaction. 

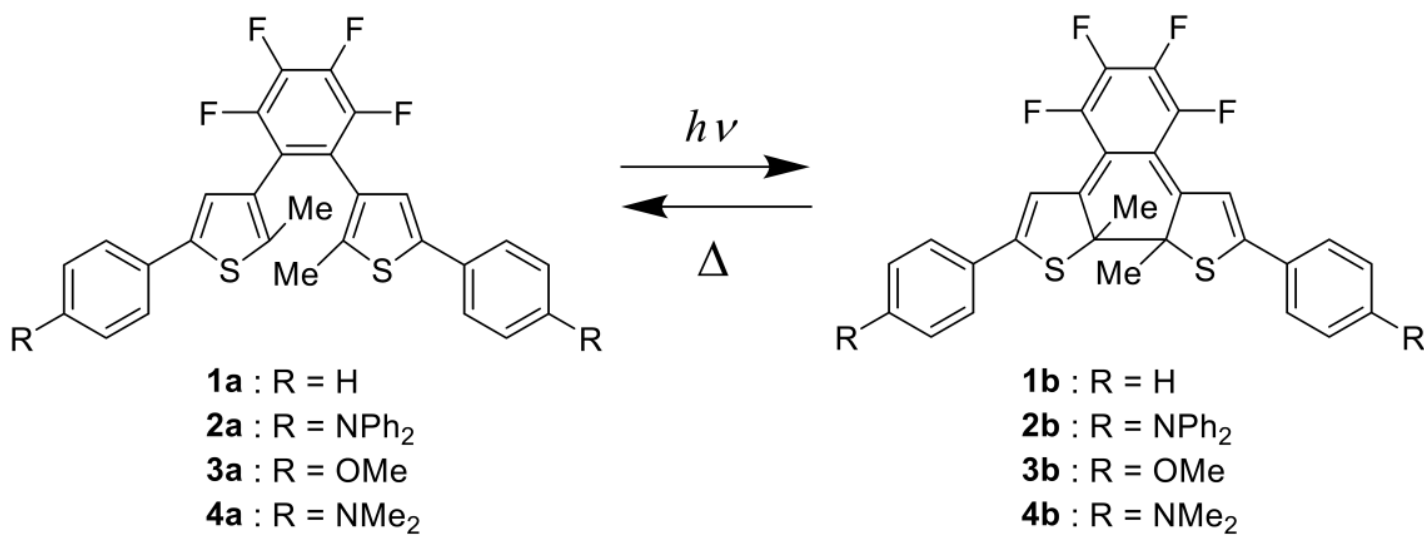

$1 b: R=H$

2b: $\mathrm{R}=\mathrm{NPh}_{2}$

3b : $\mathrm{R}=\mathrm{OMe}$

4b : $\mathrm{R}=\mathrm{NMe}_{2}$

Scheme 1. 1,2-Diarylbenzene derivatives used in this work. 


\section{Experimental Section}

\section{Materials}

Chemicals used for the syntheses were commercially available and used without further purification. Compound 1a was prepared by a method described previously. ${ }^{28}$ The protocol for the synthesis of DABs $\mathbf{2 a - 4 a}$ are given in the Supporting Information.

\section{Spectroscopic measurements}

All the solvents used were of spectroscopic grade and purified by distillation before use. ${ }^{1} \mathrm{H}$ NMR $(300 \mathrm{MHz})$ spectra were recorded on a Bruker AV-300N spectrometer using tetramethylsilane as the internal standard. High-resolution mass spectra were obtained on a Bruker FT-ICR/solariX mass spectrometer. Matrix-assisted laser desorption/ionization was used for ionization, and trans2-[3-(4-tert-butylphenyl)-2-methyl-2-propenylidene]malononitrile was used as the matrix. UVVis absorption spectra were acquired on a JASCO V-560 absorption spectrometer. The light power was measured using a Neoark PM-335A power meter. Fluorescence spectra were acquired on a JASCO FP-8300 fluorescence spectrophotometer, and the fluorescence quantum yield was with the aid of a JASCO ILF-835 integrating sphere. The sample solutions for fluorescence spectroscopic measurements were deaerated by bubbling with argon gas for $10 \mathrm{~min}$ before the measurements.

\section{Photochromic Reaction}

Transient absorption spectra were measured using a Nikon ECLIPSE E600 optical microscope equipped with Ocean Optics USB4000 fiber multichannel analyzer as the photodetector. Samples 
were irradiated using a $200 \mathrm{~W}$ mercury-xenon lamp (MORITEX MSU-6) as the light source. Monochromatic light was obtained by passing the light through a band-pass filter.

\section{Thermal Cycloreversion Reaction}

The thermal cycloreversion of DAB closed-ring isomers was carried out in $n$-hexane. The openring isomers were put in an optical quartz cuvette. The solution in the cuvette was irradiated at 313 nm using a 300W xenon lamp (Asahi Spectra MAX-301) to give the closed-ring isomers at the temperature of measurement. Monochromatic light was obtained by passing the light through a band-pass filter. The cuvette was placed in a cryostat for spectroscopic measurements (UNISOKU CoolSpek UV/CD) during the thermal cycloreversion reaction.

\section{Theoretical studies}

Geometry optimizations and harmonic frequency calculations of open-ring isomers, closed-ring isomers, and transition states were performed using Gaussian 09 Rev.C.01 program package. The transition-state search was performed with Opt $=$ TS keyword, using Berny algorithm to optimize to a transition state rather than a local minimum. Each stationary point was characterized by the number of imaginary frequencies $\left(N_{\text {Imag }}=1\right.$ for transition state and $N_{\text {Imag }}=0$ for the local minimum) and by zero-point vibrational energies. To follow unrestricted Kohn-Sham solution, the broken-symmetry (BS) guess was generated and followed using keyword Guess (mix, always) for transition state. ${ }^{33}$ The B3LYP level of density functional theory (DFT) was used in combination with a 6-31G(d) basis set. Time dependent (TD)-DFT calculation was performed at the CAMB3LYP/6-31G(d) level using the optimized molecular structures. 


\section{Results and Discussion}

\section{Molecular Design using Theoretical Calculation}

First, we attempted to predict the influence of the electron-donating groups in the $p$ position of the phenyl ring on the spectral properties of DAB. Figure 1 shows the calculated absorption spectra and the oscillator strength $(f)$ of DAB open-ring isomers calculated by TD-DFT at the CAM-B3LYP/6-31G(d)//B3LYP/6-31G(d) level. The calculated $f$ values are listed in Table S1. The maximum value of $f$ for $\mathbf{1 a}$ was observed at $270.6 \mathrm{~nm}$, which is close to the absorption maximum of $\mathbf{1 a}\left(\lambda_{\max }=285 \mathrm{~nm}\right)$. On the other hand, the maximum values of $f$ for $\mathbf{2 a}-\mathbf{4 a}$ were observed at $319.6,276.6$, and $294.7 \mathrm{~nm}$, respectively. It is evident that the absorption spectra of $\mathbf{2 a}-\mathbf{4 a}$ are red-shifted with respect to that of $1 \mathbf{a}$. The maximum $f$ values of $\mathbf{2 a}-\mathbf{4 a}$ were calculated to be $1.743,1.120$, and 1.391, respectively, which were higher than that of $\mathbf{1 a}(f=0.928)$. Therefore, theoretical calculations predicted that the introduction of electron-donating groups to 1a results in the red-shift of the absorption spectra and increases in the absorption coefficient in the open-ring isomers. The $f$ values predict that $\mathbf{2 a}$ and $\mathbf{4 a}$ are likely to have higher absorbance in the UV-A region. 


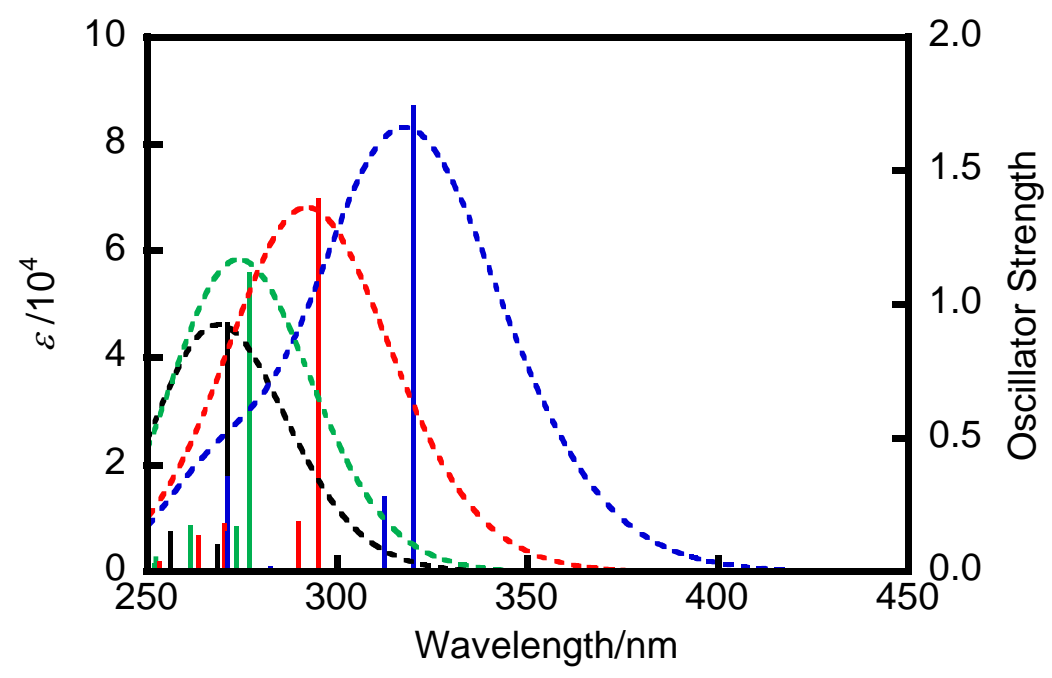

Figure 1. Calculated absorption spectra of 1a (black line), 2a (blue line), 3a (green line), and 4a (red line) by TD-DFT (CAM-B3LYP/6-31G(d)//B3LYP/6-31G(d) level of the theory), modeled with a HWHM of $2690 \mathrm{~cm}^{-1}$.

Next, we estimated the influence of the electron-donating substituents on the thermal cycloreversion. To predict the reactivity of $\mathbf{2 b}-\mathbf{4 b}$ in the thermal cycloreversion, the activation energies $\left(E_{\mathrm{a}}\right)$ required for the transformation from the closed-ring isomer to the open-ring isomer were estimated by DFT calculation (Table S2). The $E_{\mathrm{a}}$ values of $\mathbf{2 - 4}(61.27,62.02$, and $66.45 \mathrm{~kJ}$ $\mathrm{mol}^{-1}$ for $\mathbf{2 , 3}$, and $\mathbf{4}$, respectively) are higher than that of $\mathbf{1}\left(57.45 \mathrm{~kJ} \mathrm{~mol}^{-1}\right)$. Therefore, the thermal cycloreversion of $\mathbf{2 b}-\mathbf{4 b}$ is expected to be slower than that of $\mathbf{1 b}$. Thus, the introduction of the electron-donating groups at the $p$-position of the phenyl rings of 1a led to the deceleration of the thermal cycloreversion. Therefore, the electron-donating groups play an important role in determining not only the spectral properties but also the thermal cycloreversion reactivity of DABs used in this work. 


\section{Photochromic Reaction}

To study the photochromic properties of DABs, we synthesized DABs $\mathbf{2 a - 4 a}$ (details in Supporting Information) and investigated their photochromic properties in $n$-hexane. The optical and thermal properties of 1-4 are summarized in Table 1. Figure 2a shows the absorption spectra of $\mathbf{1 a}-\mathbf{4 a}$ in $n$-hexane. As predicted by TD-DFT calculations, the absorption spectra of $\mathbf{2 a}-\mathbf{4 a}$ were red-shifted in comparison with that of 1a. In addition, the absorption coefficients at $\lambda_{\max }\left(\varepsilon_{\max }\right)$ for 2a-4a were determined to be 55900, 35600, and $47400 \mathrm{M}^{-1} \mathrm{~cm}^{-1}$, respectively, which are larger than that of $1 \mathbf{a}\left(\varepsilon_{\max }=31000 \mathrm{M}^{-1} \mathrm{~cm}^{-1}\right)$. The absorption at $\lambda_{\max }$ was mainly assigned to HOMOLUMO+1 transition for $\mathbf{1 a}$ and HOMO-LUMO transition for $\mathbf{2 a - 4 a}$, respectively. The molecular orbitals related to the transitions were shown in Figure S4. The electron densities of the HOMO and LUMO+1 levels for 1a were delocalized. On the other hand, the electron density of the HOMO level of $\mathbf{2 a - 4 a}$ was localized around the aryl moieties, while that of the LUMO level was localized around the ethene bridges. Therefore, the transitions of $\mathbf{2 a - 4 a}$ exhibited an intramolecular charge transfer (ICT) character, which suggests that the red-shift in the absorption spectra of $\mathbf{2 a - 4 a}$ depends on the electron-donating ability of the substituents. In addition, the electron density of the HOMO level of $\mathbf{2 a}$ presents in the diphenylamino group, suggesting that the $\pi$-conjugation of $\mathbf{2 a}$ is longer than those of the other diarylbenzene derivatives. Therefore, $2 \mathbf{a}$ exhibited the largest redshifted absorption spectrum due to the ICT characteristics and the extending of $\pi$-conjugation. Moreover, a shoulder absorption band of $\mathbf{2 a}$ was observed at $305 \mathrm{~nm}$, which was mainly assigned to the $\mathrm{HOMO}-1-\mathrm{LUMO}+6$ transition from the aryl moieties to diphenylamino groups. 
Upon irradiation with $313 \mathrm{~nm}$ light, new absorption bands assigned to the closed-ring isomers $\mathbf{2} \mathbf{b}$ 4b appeared at the visible region, as shown in Figure $2 \mathrm{~b}$. Once the irradiation is stopped, the absorption bands rapidly disappear owing to thermal cycloreversion (Figure 2c). Thus, 2a-4a underwent photocyclization and rapid thermal cycloreversion, similar to that observed for 1a. The $\lambda_{\max }$ values of $\mathbf{2 b}-\mathbf{4 b}$ were determined to be 770,735 , and $765 \mathrm{~nm}$, respectively, all of which are red-shifted relative to that of $\mathbf{1 b}$ in $n$-hexane $\left(\lambda_{\max }=730 \mathrm{~nm}\right)$. The result is consistent with the UVvis spectra calculated by TD-DFT at the CAM-B3LYP/6-31G(d) level (Figure S5 and Table S3). The absorption bands corresponded to HOMO-LUMO transition. The red-shift in the absorption spectra of $\mathbf{2 b - 4 b}$ was ascribed to a decrease in the HOMO-LUMO gap upon the introduction of the electron-donating groups (Table S4).

In previous report, it was confirmed that 1a has high fatigue resistance for repeated photocyclization and thermal cycloreversion and photoreactivity in the polymer film. ${ }^{28}$ To confirm their properties of $\mathbf{2 a - 4 a}$, we have firstly investigated repeating cycles of the photocyclization and thermal cycloreversion of 2a-4a. Photocyclization upon irradiation with $313 \mathrm{~nm}$ light for $1.0 \mathrm{~s}$ and thermal cycloreversion at $298 \mathrm{~K}$ were alternately repeated for $\mathbf{2 a - 4 a}$ in $n$-hexane (Figure S6). After 20 cycles, a significant decrease of the absorbance in their closed-ring isomers was hardly observed. Next, the absorption spectra of the polymer films containing $\mathbf{2 a - 4 a}$, that were prepared by casting a toluene solution containing the compounds and poly(methyl methacrylate) (PMMA) (1:4 w/w) on a slide glass and drying them in air, were measured. As shown in Figure S7, appearance of the absorption bands of the closed-ring isomers upon irradiation with $313 \mathrm{~nm}$ light and rapid disappearance by the thermal cycloreversion could be observed. Therefore, these results indicate that $\mathbf{2 a - 4 a}$ also have the high fatigue resistance and the photoreactivity in the solid state as well as $1 a$. 
Table 1. Optical properties and Arrhenius parameters for thermal cycloreversion of 1,2diarylbenzene derivatives in $n$-hexane.

\begin{tabular}{|c|c|c|c|c|c|c|c|c|}
\hline & \multicolumn{2}{|c|}{ Open-ring isomer } & \multirow{2}{*}{$\begin{array}{l}\text { Closed-ring } \\
\text { isomer } \\
\lambda_{\text {max }} / \mathrm{nm}\end{array}$} & \multirow{2}{*}{$\begin{array}{l}E_{\mathrm{a}} / \\
-\mathrm{kJ} \mathrm{mol}^{-1}\end{array}$} & \multirow{2}{*}{$\begin{array}{l}E_{\mathrm{a}(\text { calcd. })} / \\
\mathrm{kJ} \mathrm{mol}^{-1 a}\end{array}$} & \multirow{2}{*}{$A / \mathrm{s}^{-1}$} & \multirow{2}{*}{$\begin{array}{l}\mathrm{k} / \mathrm{s}^{-1} \\
(298 \mathrm{~K})\end{array}$} & \multirow{2}{*}{$\begin{array}{l}t_{1 / 2} / \mathrm{ms} \\
(298 \mathrm{~K})\end{array}$} \\
\hline & $\lambda_{\max } / \mathrm{nm}$ & $\varepsilon / \mathrm{M}^{-1} \mathrm{~cm}^{-1}$ & & & & & & \\
\hline$\overline{\mathbf{1}^{b}}$ & 285 & 31000 & 730 & 66 & 57.45 & $2.1 \times 10^{12}$ & 5.34 & 130 \\
\hline 2 & 345 & 55900 & 770 & 69 & 61.27 & $2.8 \times 10^{12}$ & 2.11 & 330 \\
\hline 3 & 290 & 35600 & 735 & 71 & 62.02 & $3.7 \times 10^{12}$ & 1.36 & 510 \\
\hline 4 & 315 & 47400 & 765 & 77 & 66.45 & $2.1 \times 10^{13}$ & 0.61 & 1140 \\
\hline
\end{tabular}

${ }^{a}$ Activation energy estimated by DFT calculation. ${ }^{b}$ Ref. 28 .
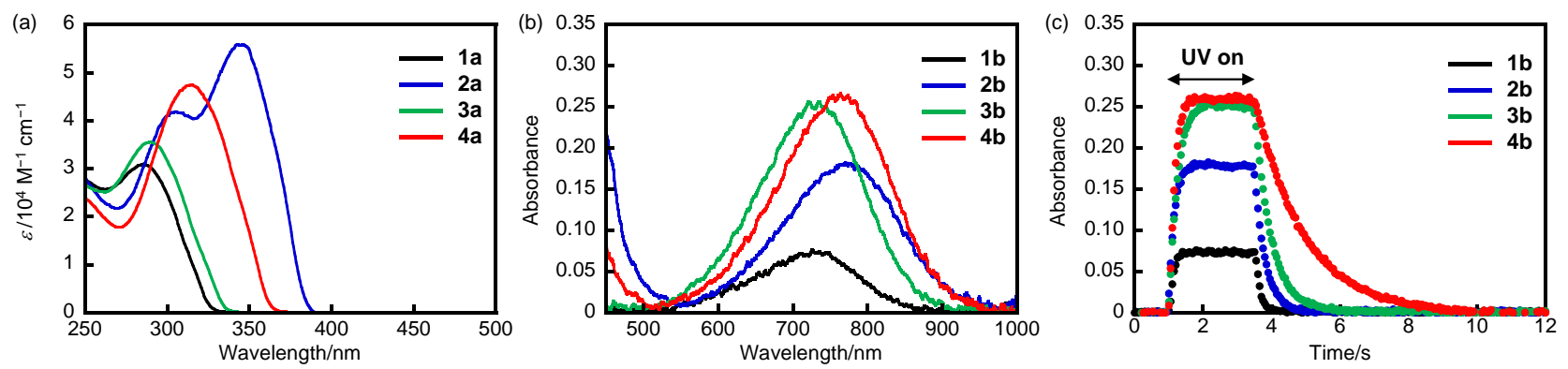

Figure 2. (a) Absorption spectra of 1a, 2a, 3a, and 4a in $n$-hexane, (b) absorption spectra of 1b, $\mathbf{2 b}, \mathbf{3 b}$, and $\mathbf{4 b}$ upon irradiation with $313 \mathrm{~nm}$ light $\left(120 \mathrm{~mW} \mathrm{~cm}^{-2}\right)$ at $298 \mathrm{~K}$ (the absorbance at 313 $\mathrm{nm}$ in the solutions of open-ring isomer was set to 1.5), and (c) change in the absorbance at $\lambda_{\max }$ upon irradiation at $313 \mathrm{~nm}$.

Compounds 2a and 4a underwent photocyclization and fast thermal cycloreversion even upon irradiation at $365 \mathrm{~nm}$ owing to the red-shifted absorption spectra (Figure S8). However, no color 
change of 1a in $n$-hexane was observed upon irradiation at $365 \mathrm{~nm}$ (Figure S9). Unfortunately, the photochromic reaction of 2a could not be observed with naked eyes, because 2a exhibited bright blue fluorescence with a fluorescence maximum at $388 \mathrm{~nm}$ and fluorescence quantum yield of 9.3\% (Figure S10). On the other hand, $4 \mathbf{a}$ in $n$-hexane underwent the photochromic reaction involving a color change from colorless to green when the solution was irradiated at $365 \mathrm{~nm}$ (Figure 3 and Video S1). Once the irradiation was stopped, the green color rapidly disappeared. Thus, the introduction of $N, N$-dimethylamino group at the $p$-position of the phenyl ring of 1a enabled us to design a $\mathrm{DAB}$ derivative that could undergo photocyclization upon irradiation with UV-A light and fast thermal cycloreversion with a half-life of a few seconds.
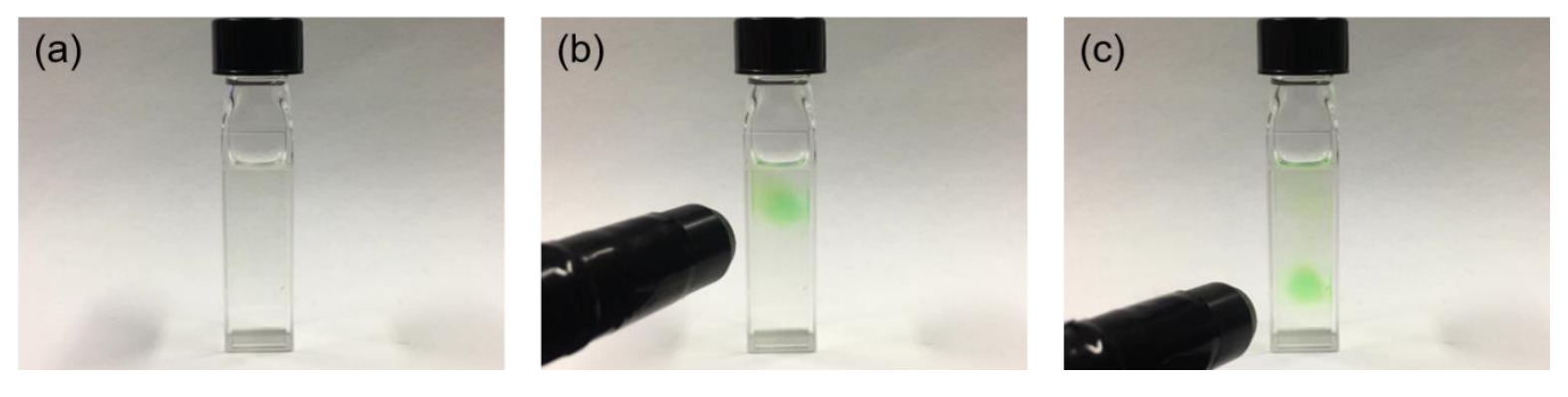

Figure 3. Photochromic reaction of $\mathbf{4 a}$ in $n$-hexane $\left([\mathbf{4 a}]=9.6 \times 10^{-3} \mathrm{M}\right)$ : (a) before photoirradiation and upon irradiating the (b) upper part and (c) the lower part of the quartz cuvette with $365 \mathrm{~nm}$ light $\left(60 \mathrm{~mW} \mathrm{~cm}^{-2}\right)$.

The absorbance of $\mathbf{1 b}-\mathbf{4 b}$ at the stationary states increased in the order of $\mathbf{1 b}, \mathbf{2 b}, \mathbf{3 b}, \mathbf{4 b}$ (Figure

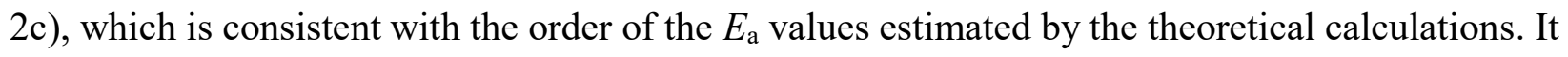
can be noted that the absorbance at the stationary state increases with increasing photocyclization 
quantum yields $\left(\Phi_{o c}\right)$ and/or decreasing rate of thermal cycloreversion. ${ }^{4}$ It is difficult to quantitatively evaluate the $\Phi_{\mathrm{oc}}$ of DABs due to the thermal instability of the closed-ring isomers at room temperature. However, the previous study on DAEs revealed that the introduction of the electron-donating groups to DAEs hardly affects the $\Phi_{\text {oc }}{ }^{31}$ Therefore, it is concluded that the absorbance of the closed-ring isomers at the stationary state is mostly affected by the rate of thermal cycloreversion.

\section{Thermal Cycloreversion Reaction}

To quantitatively evaluate the reactivities of $\mathbf{2 b} \mathbf{b} \mathbf{- 4} \mathbf{b}$ in the thermal cycloreversion, we recorded the change in the absorption of $\mathbf{2} \mathbf{b}-\mathbf{4} \mathbf{b}$ as a function of time at various temperatures (Figure 4). The absorption decay obeyed first-order kinetics (Figure S11). The reaction rate constants $(k)$ of the thermal cycloreversion of $\mathbf{2 b}-\mathbf{4 b}$ at various temperatures were calculated from the slope of the linear plots (Table S5). Figure 5 shows the temperature dependence of $k$. The $E_{\mathrm{a}}$ values and the frequency factor $(A)$ of the thermal cycloreversion were determined from the slope and intercept of the linear Arrhenius plots. The results are summarized in Table 1. The $E_{\mathrm{a}}$ values

of $\mathbf{2 b}-\mathbf{4} \mathbf{b}$ were 69,71 , and $77 \mathrm{~kJ} \mathrm{~mol}^{-1}$, respectively. The measured $E_{\text {a }}$ values are consistent with the $E_{\mathrm{a}}$ values calculated by DFT (Figure S12). Furthermore, the $A$ values for $\mathbf{2 b}-\mathbf{4 b}$ were estimated to be $2.8,3.7$, and $21 \times 10^{12} \mathrm{~s}^{-1}$, respectively. Using the estimated $E_{\mathrm{a}}$ and $A$ values, $t_{1 / 2}$ of $\mathbf{1 b}-\mathbf{4 b}$ at $298 \mathrm{~K}$ were calculated to be 130,330 , and 510 , and $1140 \mathrm{~ms}$, respectively. Thus, $t_{1 / 2}$ also increased in the same order as the absorbance at the stationary state. This confirmed that the absorbance of the closed-ring isomers at the stationary state increased with decreasing rate of thermal cycloreversion. 

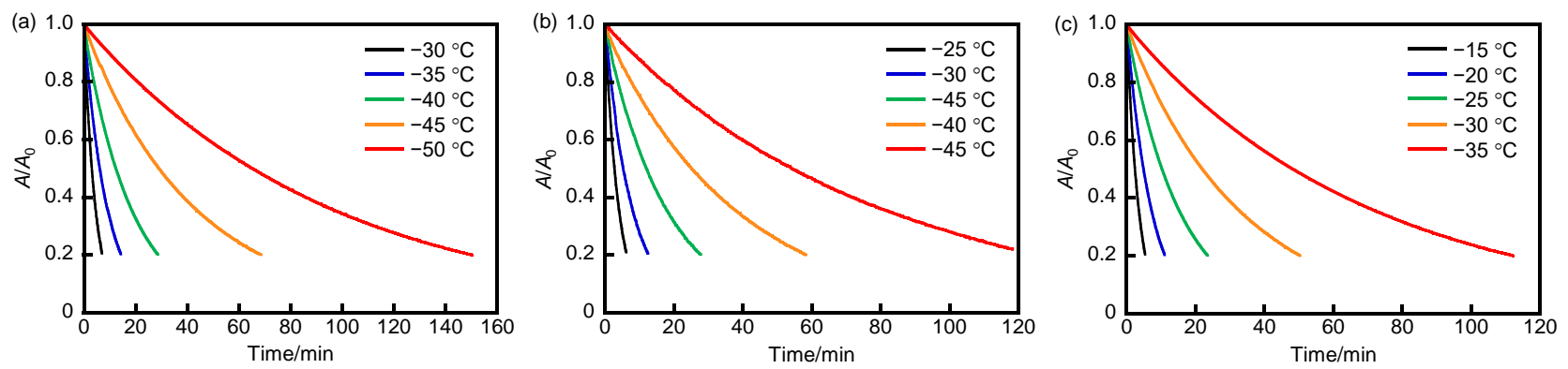

Figure 4. Absorption decay curves at $\lambda_{\max }$ for (a) $\mathbf{2 b}$, (b) $\mathbf{3 b}$, and (c) $\mathbf{4} \mathbf{b}$ in $n$-hexane at various temperatures.

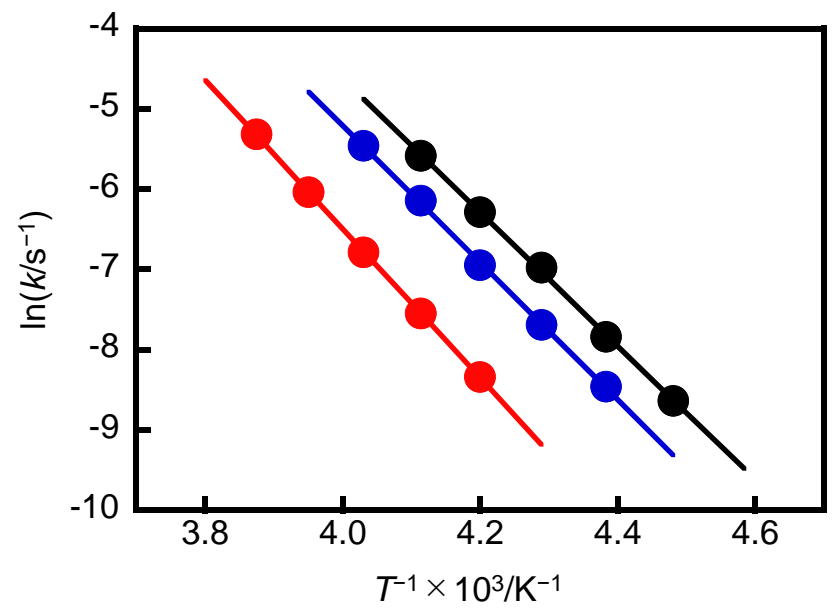

Figure 5. Temperature dependence of the rate constant $(k)$ for thermal cycloreversion of $\mathbf{2 b}$ (black circle), $\mathbf{3 b}$ (blue circle), and $\mathbf{4 b}$ (red circle).

Correlation between Electron-Donating Ability of the Substituents and Thermal Cycloreversion 
To elucidate the relationship between the electron-donating ability of the substituents and the thermal cycloreversion, $\log \left(k / k_{\mathrm{H}}\right)$ at $298 \mathrm{~K}$ was plotted as a function of Hammett's substituent constant $\left(\sigma_{\mathrm{p}}\right)^{34}$ (Figure 6a), where $k_{\mathrm{H}}$ is the rate constant of $\mathbf{1 b}$. $\sigma_{\mathrm{p}}$ is a typical parameter indicating the electron-donating or withdrawing ability of a substituent and useful for understanding the relationship between the rate of the reaction and the substituent effects and the reaction mechanism. ${ }^{35-38}$ As can be seen in Figure 6a, it is evident that $\log \left(k / k_{\mathrm{H}}\right)$ is linearly dependent on $\sigma_{\mathrm{p}}$ $\left(r^{2}=0.886\right)$. The reaction constant $(\rho)$, as determined from the slope of the linear plot, was 1.29, which is positive. Therefore, the thermal cycloreversion is retarded in proportion to the increase in the electron-donating ability of the substituents introduced at the $p$-position of the phenyl ring of DABs. A positive $\rho$ indicates an increase in the negative charge (or a decrease in the positive charge) at the reaction center in the transition state. Mulliken charges at the reacting carbon atoms of DABs estimated by DFT calculation (Table S6) were negative in the closed-ring isomer and the transition state. The electrostatic potentials were also negative as well as Mulliken charges (Table S7). Moreover, the values in the transition state increased in comparison with those in the closedring isomer, as evident from the Hammett plot. Thus, the Hammett plot revealed that the thermal cycloreversion of DABs is decelerated with increasing electron-donating ability of the substituent, owing to the negative charge of the reacting carbon atoms.
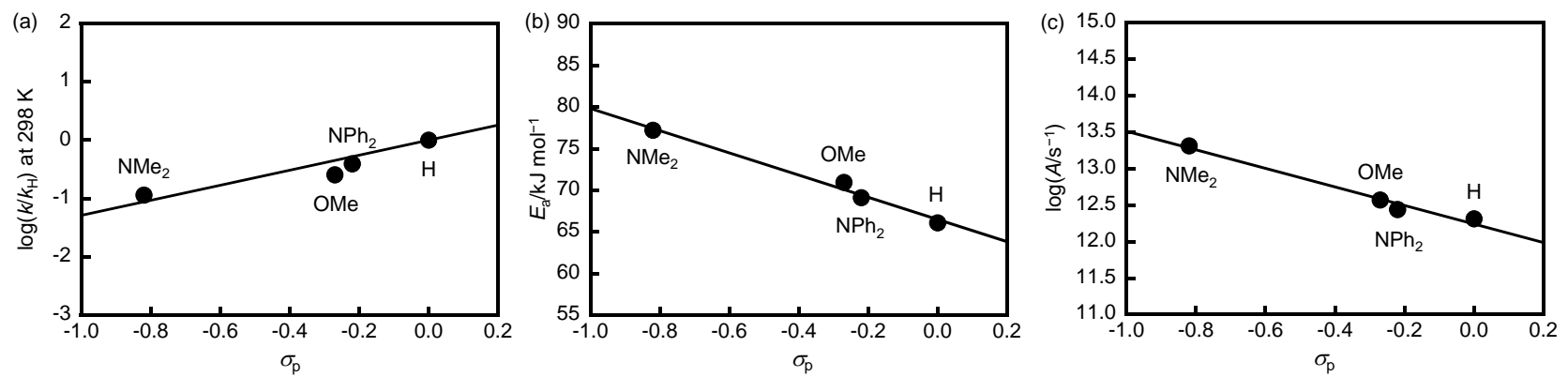
Figure 6. Hammett plots of the (a) rate constant at $298 \mathrm{~K}\left(r^{2}=0.886\right)$, (b) activation energy $\left(r^{2}=\right.$ $0.984)$, and (c) frequency factor $\left(r^{2}=0.978\right)$ for the thermal cycloreversion.

Since the rate of thermal cycloreversion depends on $E_{\mathrm{a}}$ and $A$, it is expected that $E_{\mathrm{a}}$ and/or $A$ will be linearly dependent on $\sigma_{\mathrm{p}}$. Figure $6 \mathrm{~b}$ shows the relationship between $E_{\mathrm{a}}$ and $\sigma_{\mathrm{p}}$. $E_{\mathrm{a}}$ exhibited a good correlation with $\sigma_{\mathrm{p}}\left(r^{2}=0.984\right)$, indicating that the activation energy for the transformation from the closed-ring isomer to the open-ring isomer increases with increasing electron-donating ability of the substituent. Moreover, $\log (A)$ and $\sigma_{\mathrm{p}}$ were linearly dependent, with $r^{2}=0.978$ (Figure 6c). Thus, the electron-donating groups affect not only the activation energy but also the frequency factor of the thermal cycloreversion of DABs. Increasing the electron-donating ability increases $E_{\mathrm{a}}$ and $\log (A)$ and decreases $\log (k)$. This indicates that the change in $E_{a}$ by the electron-donating substituents primarily affects the rate of thermal cycloreversion; the influence on the frequency factor is rather small.

The reactivity in thermal cycloreversion, i.e. $E_{\mathrm{a}}$, relates to the energy difference $(\Delta E)$ between the closed-ring isomer and open-ring isomer in the ground state. Smaller $\Delta E$ leads to higher $E_{\mathrm{a}}$ and thus, a decrease in the reactivity in the thermal cycloreversion. This is known as the Bell-EvansPolanyi (BEP) principle. ${ }^{39}$ The $\Delta E$ values of $\mathbf{1}-\mathbf{4}$ were determined to be $112.23,103.62,106.36$, and $98.58 \mathrm{~kJ} \mathrm{~mol}^{-1}$, respectively, by DFT calculation (Table S2). $E_{\mathrm{a}}$ exhibited a linear relationship with $\Delta E$ (Figure S13), suggesting that the thermal cycloreversion of DABs could be interpreted based on the BEP principle. When the closed-ring isomer is relatively stabilized with respect to the open-ring isomer, the reaction coordinates in the transition state shift toward the open-ring isomer, as shown in Figure 7. Thus, the geometry of DABs in the transition state should be closer 
to that of the open-ring isomer, with relative stabilization of the closed-ring isomer. This is known as Hammond's postulate. ${ }^{39}$ To evaluate the geometry in the transition state, the distance between the reacting carbon atoms and torsion angle of the methyl group on the reacting carbon atom relative to the thiophene ring were calculated (Table S6). ${ }^{40}$ Figure 8 shows the relationship of these parameters relative to $E_{\mathrm{a}}$; the average value of two torsion angles was used. As can be seen, both the parameters increased with increasing $E_{\mathrm{a}}$. This indicates that the geometry of the transition state of the more thermally stable DAB is closer to the open-ring isomer. Moreover, these parameters for the open- and closed-ring isomers were nearly constant (Figure S14), suggesting that the potential energy surface of the closed-ring isomer is relatively stabilized without a change in the reaction coordinate of both the open- and closed-ring isomers (Figure 7). It is thus concluded that since the reacting carbon atoms have negative charge in the transition state, the potential energy surface of the closed-ring isomer is relatively stabilized with respect to the open-ring isomer upon the introduction of the electron-donating substituents at the $p$-position of the phenyl ring, thereby resulting in an increase in $E_{\mathrm{a}}$, a decrease in $\Delta E$, and a shift in the reaction coordinate of the transition state toward to the open-ring isomer. As a result, the rate of thermal cycloreversion is lowered, and the extent of decrease is proportional to the electron-donating ability of the substituents. 


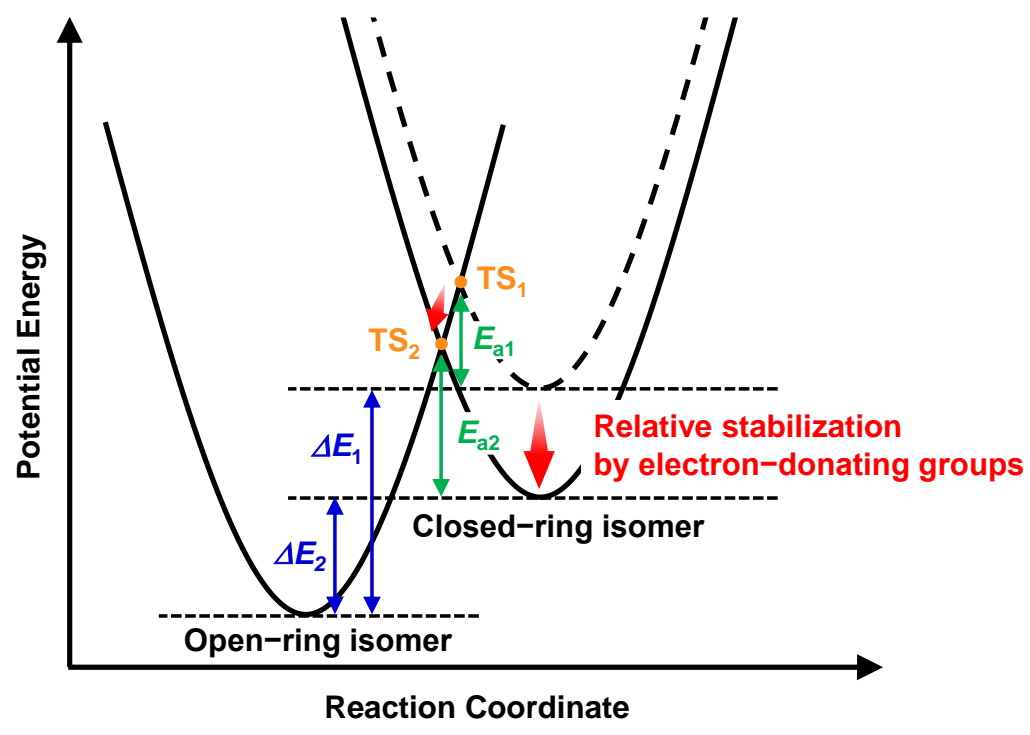

Figure 7. Correlation between the activation energy $\left(E_{\mathrm{a}}\right)$ and energy difference $(\Delta E)$. 

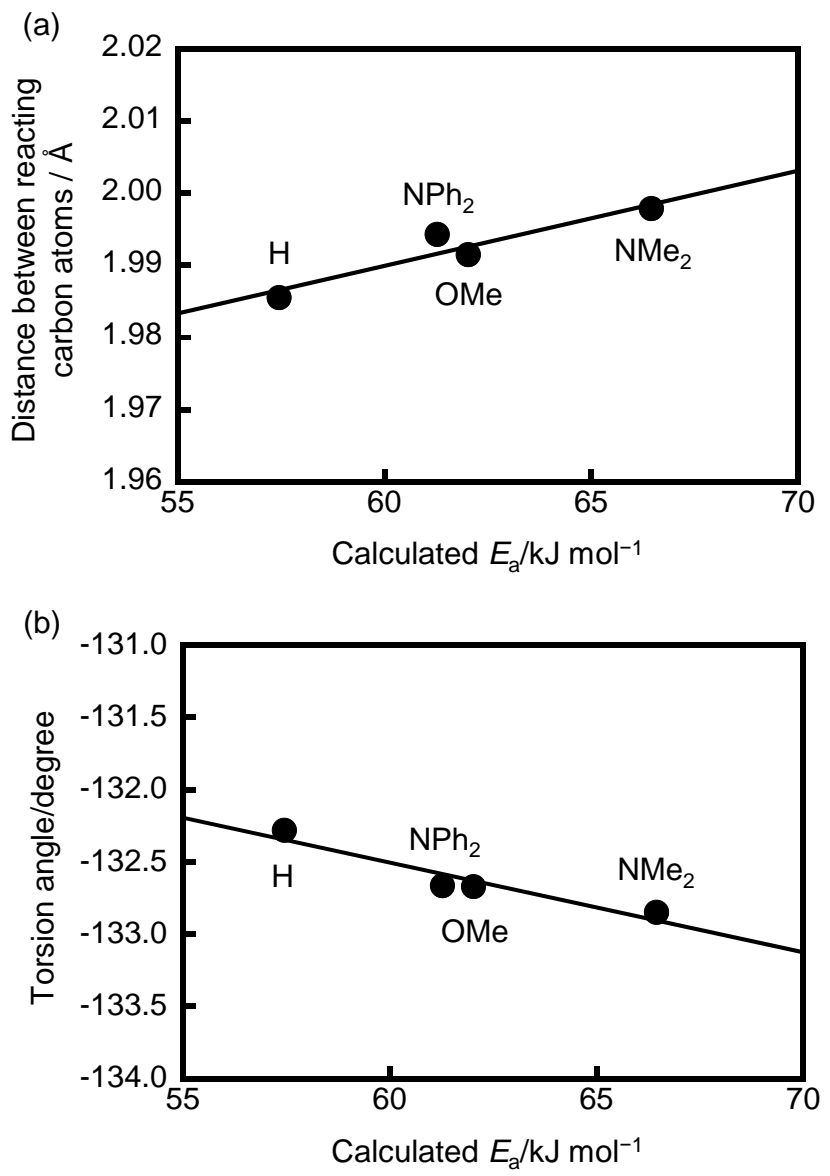

Figure 8. (a) Distance between reacting carbon atoms $\left(r^{2}=0.880\right)$ and (b) torsion angle of methyl group on the reacting carbon atom relative to the thiophene ring $\left(r^{2}=0.910\right)$ in the transition state. 


\section{Conclusion}

In summary, we synthesized 1,2-diarylbenzene (DAB) derivatives bearing various electron-donating substituents at the $p$-position of the benzene ring with the aim of tuning their optical and thermal properties. The substituted DABs exhibited red-shifted absorption spectra, higher absorption coefficients, and slower thermal cycloreversion in comparison with the unsubstituted DAB. This was also consistent with the predictions of the theoretical calculations. Moreover, the rate constants of the thermal cycloreversion were well correlated with Hammett's substituent constant, suggesting that the rate of thermal cycloreversion is lowered in proportion to the electron-donating ability of the substituent. This work would provide a guideline for designing DABs with desired optical and thermal properties. 


\section{ASSOCIATED CONTENT}

Supporting Information. The Supporting Information is available free of charge on the ACS

Publications website at DOI: ****. Syntheses of 1,2-diarylbenzene derivatives, Figures S1-S14, and Tables S1-S19 (PDF)

\section{AUTHOR INFORMATION}

\section{Corresponding Author}

*Email: kitagawa@,osaka-cu.ac.jp and kobatake@a-chem.eng.osaka-cu.ac.jp.

\section{Notes}

The authors declare no competing financial interest.

\section{ACKNOWLEDGMENT}

This work was partly supported by JSPS KAKENHI Grant Numbers JP26107013 in Scientific Research on Innovative Areas "Photosynergetics" (S. K.), JSPS KAKENHI Grant Number JP16K17896 in Scientific Research for Young Scientists B (D. K.) and JSPS KAKENHI Grant Number 18J10399 in Scientific Research for JSPS fellow (T. N.).

\section{REFERENCES}

1. Trozzolo, A. M.; Leslie, T. M.; Sarpotdar, A. S.; Small, R. D.; Ferraudi, G. J.; Dominh, T.; Hartless, R. L., Photochemistry of Some 3-Membered Heterocycles. Pure Appl. Chem. 1979, 51, 261-270. 
2. Irie, M.; Fukaminato, T.; Sasaki, T.; Tamai, N.; Kawai, T., Organic Chemistry: A Digital Fluorescent Molecular Photoswitch. Nature 2002, 420, 759-760.

3. Jia, C.; Migliore, A.; Xin, N.; Huang, S.; Wang, J.; Yang, Q.; Wang, S.; Chen, H.; Wang, D.; Feng, B.; et al. Covalently Bonded Single-Molecule Junctions with Stable and Reversible Photoswitched Conductivity. Science 2016, 352, 1443-1445.

4. Inagaki, Y.; Kobayashi, Y.; Mutoh, K.; Abe, J., A Simple and Versatile Strategy for Rapid Color Fading and Intense Coloration of Photochromic Naphthopyran Families. J. Am. Chem. Soc. 2017, 139, 13429-13441.

5. Tong, F.; Hanson, M. P.; Bardeen, C. J., Analysis of Reaction Kinetics in the Photomechanical Molecular Crystal 9-Methylanthracene Using an Extended Finke-Watzky Model. Phys. Chem. Chem. Phys. 2016, 18, 31936-31945.

6. Zhu, L.; Tong, F.; Salinas, C.; Al-Muhanna, M. K.; Tham, F. S.; Kisailus, D.; Al-Kaysi, R. O.; Bardeen, C. J., Improved Solid-State Photomechanical Materials by Fluorine Substitution of 9-Anthracene Carboxylic Acid. Chem. Mater. 2014, 26, 6007-6015.

7. Fujita, K.; Hatano, S.; Kato, D.; Abe, J., Photochromism of a Radical Diffusion-Inhibited Hexaarylbiimidazole Derivative with Intense Coloration and Fast Decoloration Performance. Org. Lett. 2008, 10, 3105-3108.

8. Kishimoto, Y.; Abe, J., A Fast Photochromic Molecule That Colors Only under UV Light. J. Am. Chem. Soc. 2009, 131, 4227-4229.

9. Yamashita, H.; Ikezawa, T.; Kobayashi, Y.; Abe, J., Photochromic Phenoxyl-Imidazolyl 
Radical Complexes with Decoloration Rates from Tens of Nanoseconds to Seconds. J. Am. Chem. Soc. 2015, 137, 4952-4955.

10. Ikezawa, T.; Mutoh, K.; Kobayashi, Y.; Abe, J., Thiophene-Substituted PhenoxylImidazolyl Radical Complexes with High Photosensitivity. Chem. Commun. 2016, 52, 2465-2468.

11. Ishii, N.; Kato, T.; Abe, J., A Real-Time Dynamic Holographic Material Using a Fast Photochromic Molecule. Sci. Rep. 2012, 2, 819.

12. Kobayashi, Y.; Abe, J., Real-Time Dynamic Hologram of a 3D Object with Fast Photochromic Molecules. Adv. Opt. Mater. 2016, 4, 1354-1357.

13. Tomasulo, M.; Sortino, S.; White, A. J. P.; Raymo, F. M., Fast and Stable Photochromic Oxazines. J. Org. Chem. 2005, 70, 8180-8189.

14. Tomasulo, M.; Sortino, S.; Raymo, F. M., Bichromophoric Photochromes Based on the Opening and Closing of a Single Oxazine Ring. J. Org. Chem. 2008, 73, 118-126.

15. Cusido, J.; Impellizzeri, S.; Raymo, F. M., Molecular Strategies to Read and Write at the Nanoscale with Far-Field Optics. Nanoscale 2011, 3, 59-70.

16. Deniz, E.; Tomasulo, M.; Cusido, J.; Yildiz, I.; Petriella, M.; Bossi, M. L.; Sortino, S.; Raymo, F. M., Photoactivatable Fluorophores for Super-Resolution Imaging Based on Oxazine Auxochromes. J. Phys. Chem. C 2012, 116, 6058-6068.

17. Fukaminato, T.; Sasaki, T.; Kawai, T.; Tamai, N.; Irie, M., Digital Photoswitching of Fluorescence Based on the Photochromism of Diarylethene Derivatives at a Single-Molecule Level. J. Am. Chem. Soc. 2004, 126, 14843-14849. 
18. Matsuda, K.; Irie, M., A Diarylethene with Two Nitronyl Nitroxides: Photoswitching of Intramolecular Magnetic Interaction. J. Am. Chem. Soc. 2000, 122, 7195-7201.

19. Taguchi, M.; Nakagawa, T.; Nakashima, T.; Adachi, C.; Kawai, T., Photo-Patternable Electroluminescence Based on One-Way Photoisomerization Reaction of Tetraoxidized Triangle Terarylenes. Chem. Commun. 2013, 49, 6373-6375.

20. Delaire, J. A.; Nakatani, K., Linear and Nonlinear Optical Properties of Photochromic Molecules and Materials. Chem. Rev. 2000, 100, 1817-1846.

21. Irie, M.; Fukaminato, T.; Matsuda, K.; Kobatake, S., Photochromism of Diarylethene Molecules and Crystals: Memories, Switches, and Actuators. Chem. Rev. 2014, 114, 12174-277.

22. Kitagawa, D.; Kobatake, S., Strategy for Molecular Design of Photochromic Diarylethenes Having Thermal Functionality. Chem. Rec. 2016, 16, 2005-2015.

23. Shirinian, V. Z.; Lvov, A. G.; Bulich, E. Y.; Zakharov, A. V.; Krayushkin, M. M., Novel Photochromic Diarylethenes Bearing an Imidazole Moiety. Tetrahedron Lett. 2015, 56, 5477-5481.

24. Kawai, S.; Nakashima, T.; Atsumi, K.; Sakai, T.; Harigai, M.; Imamoto, Y.; Kamikubo, H.; Kataoka, M.; Kawai, T., Novel Photochromic Molecules Based on 4,5-Dithienyl Thiazole with Fast Thermal Bleaching Rate. Chem. Mater. 2007, 19, 3479-3483.

25. Yang, Y. H.; Xie, Y. S.; Zhang, Q.; Nakatani, K.; Tian, H.; Zhu, W. H., AromaticityControlled Thermal Stability of Photochromic Systems Based on a Six-Membered Ring as Ethene Bridges: Photochemical and Kinetic Studies. Chem. Eur. J. 2012, 18, 11685-11694.

26. Uchida, K.; Matsuoka, T.; Sayo, K.; Iwamoto, M.; Hayashi, S.; Irie, M., Thermally 
Reversible Photochromic Systems. Photochromism of a Dipyrrolylperfluorocyclopentene. Chem. Lett. 1999, 28, 835-836.

27. Inaba, K.; Iwai, R.; Morimoto, M.; Irie, M., Thermally Reversible Photochromism of Dipyrrolylethenes. Photochem. Photobiol. Sci. 2019, 18, 2136-2141.

28. Kitagawa, D.; Nakahama, T.; Nakai, Y.; Kobatake, S., 1,2-Diarylbenzene as Fast T-Type Photochromic Switch. J. Mater. Chem. C 2019, 7, 2865-2870.

29. Kobatake, S.; Irie, M., Synthesis and Photochromism of Diarylethenes with Isopropyl Groups at the Reactive Carbons and Long Pi-Conjugated Heteroaryl Groups. Chem. Lett. 2003, 32, 1078-1079.

30. Nakamura, S.; Irie, M., Thermally Irreversible Photochromic Systems. A Theoretical Study. J. Org. Chem. 1988, 53, 6136-6138.

31. Irie, M.; Sakemura, K.; Okinaka, M.; Uchida, K., Photochromism of Dithienylethenes with Electron-Donating Substituents. J. Org. Chem. 1995, 60, 8305-8309.

32. Gilat, S. L.; Kawai, S. H.; Lehn, J. M., Light-Triggered Molecular Devices - Photochemical Switching of Optical and Electrochemical Properties in Molecular Wire Type Diarylethene Species. Chem. Eur. J. 1995, 1, 275-284.

33. Patel, P. D.; Masunov, A. E., Theoretical Study of Photochromic Compounds: Part 3. Prediction of Thermal Stability. J. Phys. Chem. C 2011, 115, 10292-10297.

34. Hansch, C.; Leo, A.; Taft, R. W., A Survey of Hammett Substituent Constants and Resonance and Field Parameters. Chem. Rev. 1991, 91, 165-195. 
35. Berman, E.; Fox, R. E.; Thomson, F. D., Photochromic Spiropyrans. I. The Effect of Substituents on the Rate of Ring Closure. J. Am. Chem. Soc. 1959, 81, 5605-5608.

36. Levy, D.; Avnir, D., Effects of the Changes in the Properties of Silica Cage Along the Gel/Xerogel Transition on the Photochromic Behavior of Trapped Spiropyrans. J. Phys. Chem. 1988, $92,4734-4738$.

37. Cordes, T.; Schadendorf, T.; Priewisch, B.; Rück-Braun, K.; Zinth, W., The Hammett Relationship and Reactions in the Excited Electronic State: Hemithioindigo Z/EPhotoisomerization. J. Phys. Chem. A 2008, 112, 581-588.

38. Broman, S. L.; Nielsen, M. B., Dihydroazulene: From Controlling Photochromism to Molecular Electronics Devices. Phys. Chem. Chem. Phys. 2014, 16, 21172-21182.

39. Carey, F. A.; Sundberg, R. J., Advanced Organic Chemistry: Part A: Structure and Mechanisms; Springer Science \& Business Media, 2007.

40. Li, X.; Zou, Q.; Ågren, H., Photochromic Diarylethenes with Heterocyclic Aromatic Rings: Correlation between Thermal Bistability and Geometrical Characters of Transition States. J. Phys. Chem. A 2015, 119, 9140-9147. 
TOC
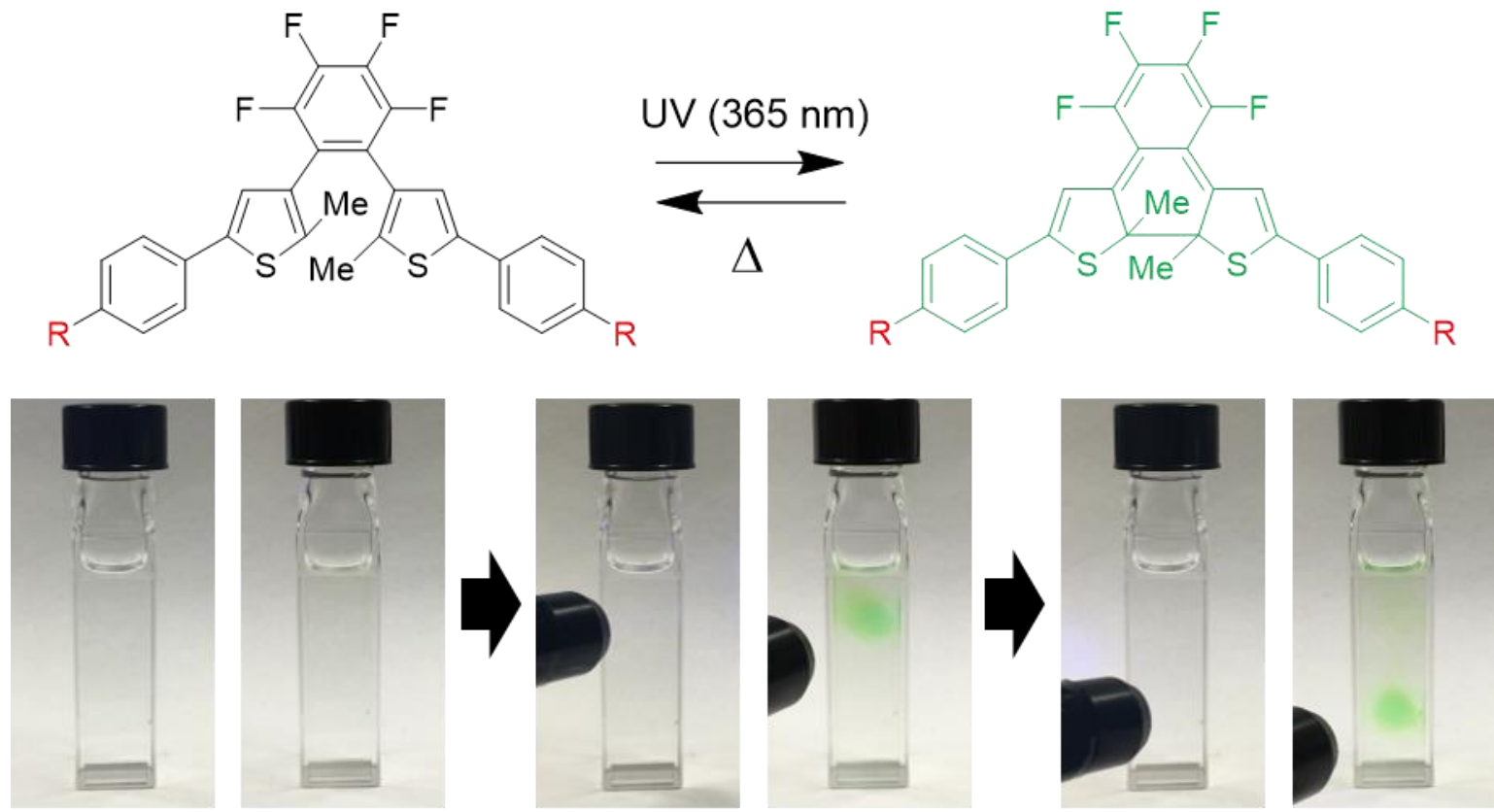

$$
\mathrm{R}=\mathrm{H} \quad \mathrm{R}=\mathrm{NMe}_{2}
$$

